\title{
REPRESENTACIÓN CORTESANA EN UNOS LIBROS DE CABALLERÍAS RENACENTISTAS: LA CONVERSACIÓN Y LA FIESTA EN EL AMADÍS DE GAULA Y EN EL ESFERAMUNDI DE GRECIA ${ }^{1}$
}

\author{
Anna Bognolo \\ (Università di Verona) \\ anna.bognolo@,univr.it
}

\section{RESUMEN}

El artículo presenta dos casos ejemplares, a partir de la definición del perfecto cortesano elaborada por Castiglione en su diálogo Il Cortegiano, y de los comentarios de Amedeo Quondam sobre la importancia, en esta «forma del vivere», de la conversación y de las habilidades cortesanas. La «gracia» de la vida de corte se muestra en los libros de caballerías; el análisis de dos episodios del Amadís y del Esferamundi de Grecia a distancia de 60 años, entre España e Italia, permite notar el perdurar de esta forma de vida en sus varios matices, donde las variaciones más maduras acentúan los detalles maravillosos de palacios y jardines y destacan el protagonismo femenino.

PALABRAS CLAVE: Amadís de Gaula; Esferamundi de Grecia; Il Cortegiano; protagonismo femenino.

\section{COURT REPRESENTATION IN SOME RENAISSANCE ROMANCES OF CHIVALRY: THE CONVERSATION AND THE FESTIVAL JOURNEY IN THE $A M A D I ́ S ~ D E ~ G A U L A$ AND IN THE SFERAMUNDI $D I G R E C I A$}

\begin{abstract}
The article presents two exemplary cases, based on the definition of the perfect courtier elaborated by Castiglione in his dialogue Il Cortegiano, and on Amedeo Quondam's comments on the importance, in this «form of life», of conversation and courtesans' skills. The «grace» of court life is shown in the chivalric

\footnotetext{
${ }^{1}$ El presente trabajo se inscribe en el marco del "ProgettoMambrino", www.mambrino.it [fecha de consulta: 4/5/2021], y del "Progetto di eccellenza: Le Digital Humanitiesapplicatealle lingue e letteraturestraniere del Dipartimento de Lingue y letteratureStraniere" de la Università de Verona, http://www.dlls.univr.it/?ent=progetto\&id=5327 [fecha de consulta: 4/5/2021]; y en el "Progetto PRIN 2017 Mapping Chivalry. Spanish Romances of chivalry from Renaissance to XXI century: a Digital approach" (2017JA5XAR), https://www.univr.it/it/iniziative/-/evento/8576?p auth=ZcGFg kei [fecha de consulta: 4/5/2021].
} 
books; the analysis of two episodes of the Amadis and the Sferamundi of Greece at a distance of 60 years, between Spain and Italy, makes it possible to note the persistence of this way of life in its various nuances, where the more mature variations accentuate the wonderful details of palaces and gardens and they highlight female protagonism.

KEY WORDS: Amadís de Gaula; Esferamundi de Grecia; Il Cortegiano; female protagonism.

Cuando el Libro del Cortegiano de Castiglione salió de la imprenta por Aldo Manuzio (Venecia, 1528) la civilización espléndida allí retratada era un recuerdo del pasado. Los conflictos históricos culminados en el Saco de Roma estaban lejos de resolverse y dejaban cicatrices indelebles en la conciencia de los intelectuales. Sin embargo, en la cultura de las cortes el libro se impone en un presente atemporal más allá de la historia; la aristocracia europea lo adopta como un código homogéneo y fuerte e Il Cortegiano se convierte en la gramática de la corte hasta la revolución francesa y más allá.

La idea del perfecto caballero cortesano toma forma en España en varias imágenes ejemplares: baste recordar, por un lado, el retrato del poeta Garcilaso de la Vega y, por el otro, los héroes de papel de los nuevos libros de caballerías del siglo XVI. Lejos de representar un lastre medieval, estos relatos, resultado de un proceso de imitación y renovación con más de un siglo de recorrido, promueven un laboratorio de reinvención y modernización de la literatura cortesana medieval que pasa su legado a la Europa del pleno Renacimiento ${ }^{2}$. Muchos géneros literarios introdujeron en sus páginas los presupuestos filosóficos de la cultura de la corte; se han estudiado estos rasgos en la novela pastoril, en la novela sentimental y en los cancioneros, como también en los tratados de amor y en los diálogos de tipo neoplatónico derivados del mismo Castiglione o a menudo asociados a él, como el coevo Gli Asolani de Pietro Bembo, publicado por el mismo Manuzio en 1505 y en segunda edición revisada en 1530. En realidad, los libros de caballerías no suelen tomarse en cuenta: todavía se han leído poco y se suelen considerar como una imitación tardía de la cultura ultra-pirenaica medieval. En cambio, como han demostrado recientemente estudiosos del nivel de Juan Manuel Cacho Blecua, M. ${ }^{a}$ Carmen Marín Pina, Alberto del Río Nogueras, M. ${ }^{a}$ Rosario Aguilar Perdomo y muchos otros, los libros de

\footnotetext{
2 Para una definición del corpus de los libros de caballerías, que comprende unas 80 obras, ver Daniel Eisenberg y M. ${ }^{a}$ Carmen Marín Pina, Bibliografía de los libros de caballerías castellanos (Zaragoza: Prensas Universitarias de Zaragoza, 2000); Antología de los libros de caballerías castellanos, ed. José Manuel Lucía Megías (Alcalá de Henares: Centro de Estudios Cervantinos, 2001); José Manuel Lucía Megías, "Libros de caballerías castellanos: textos y contextos", Edad de Oro 21 (2002): 9-60, https://doi.org/10.15366/edadoro2002.21. El libro de Pedro M. Cátedra, El sueño caballeresco. De la caballería de papel al sueño real de don Quijote (Madrid: Abada Editores, 2007) muestra cómo la caballería de papel estaba estrechamente relacionada con la realidad.
} 
caballerías son una mina, no solamente de pasatiempos, sino de pasatiempos cortesanos. Hay que mirarlos también desde esta perspectiva para apreciar los tesoros que conservan, efigies de la cultura de su época, el Renacimiento, imágenes cuanto se quiera idealizadas, pero sugerentes, que nos brindan mucha información. Nos interesa mostrar entonces en qué medida el imaginario de los libros de las caballerías se acerca al retrato conformado por el gran libro europeo que construye el modelo del hombre renacentista y la imagen de la corte, esta «forma de vida», como la llamó Amedeo Quondam, que fue reproducida como un macro código universal internacional desde Urbino a Londres o Madrid y, a pesar de sus contradicciones, funcionó como texto básico, como repertorio de referencia al cual atenerse ${ }^{3}$.

Este mismo proceso de modelización pasó a través de los libros de caballerías, empezando por el Amadís hasta el final de siglo. No fue una casualidad: el Amadís fue considerado un manual de cortesanía basado en aspectos de la conversación y la retórica del discurso, no solamente en España sino sobre todo en Francia y en Inglaterra, a partir del éxito fulgurante de la elegante traducción encargada por Francisco I a Nicolas Herberay des Essart (1540-1548), pronto recibida de manera entusiasta por la aristocracia francesa, y de aquel Trésor des livres d'Amadis, colección de fragmentos escogidos (cartas, discursos, carteles de desafío, arengas, declaraciones y lamentos de amor) sacados de las adaptaciones de Herberay y sus sucesores para servir de refinado modelo de urbanidad y elocuencia; de sus veinticuatro ediciones entre 1559 y 1606 pudo decir Edwin B. Place que influyeron en Europa más que El Cortesano ${ }^{4}$.

\footnotetext{
3 Amedeo Quondam, en su "Introduzione" a Baldassarre Castiglione, Il libro del Cortegiano (Milán: Garzanti, 1981), VII-LI, XXXVI-XLV, observa que, a pesar de ser leído como un texto coherente y unitario, El Cortesano es un texto ambiguo, marcado por inquietudes y contradicciones. El modelo cortesano renacentista, que se sitúa fuera del tiempo en una duración sin historia, sublima en armonía y equilibrio la relación de dependencia y el conflicto con el poder. Sobre la centralidad de la conversación, Amedeo Quondam, La conversazione. Un modello italiano (Roma: Donzelli, 2007). Sobre la larga duración del código, Mario Domenichelli, Cavaliere e gentiluomo. Saggio sulla cultura aristocratica in Europa (1513-1915) (Roma: Bulzoni, 2002).

${ }^{4}$ Le trésor des Amadis: contenant les épitres, complaintes, concions, harangues, deffis \& cartels, recueillis des douze livres d'Amadis de Gaule pour servir d'exemple à ceus qui désirent apprendre à bien écrire missives, ou parler français (Amberes: Christophe Plantin, 1560); reimpreso y enriquecido con varios títulos, por ejemplo Le Tresor de tous les livres d'Amadis de Gaule. Contenant les Harangues, Epistres, Cancions, Lettres missiues, Denandes, Responces, Repliques, Sentences, Cartels, Complaintes, \& autres choses, les plus excellentes, pour influire la jeune noblesse Francoise a l'elocuence, grace, vertu, \& generosité (Lyon: Jean Huguetan, 1582). En opinión de Place, el Trésor "had more influence in the uncultured French upper class of the Renaissance than any other courtesy book", cfr. Edwin B. Place, "El Amadís de Montalvo como manual de cortesanía en Francia", Revista de Filología Española 38 (1954): 151-169. Ver también Anthony C. Mottola, The "Amadís de Gaula" in Spain and in France, tesis doctoral (Fordham University, 1962), 159 y ss.; John J. O'Connor, "Amadís de Gaule" and Its Influence on Elizabethan Literature (New Brunswick: Rutgers University Press, 1970), 6162, que revisa las declaraciones de los traductores que invitan a la imitación; Sylvia Roubaud, "Libros de caballerías en Francia", en Amadís de Gaula, 1508. Quinientos años de libros de caballerías, ed. José Manuel Lucía Megías (Madrid: Biblioteca Nacional de España, 2008), 319-331; cfr. M. ${ }^{a}$ Carmen Marín Pina, "Las cartas de amor caballerescas como modelos epistolares", en La recepción del texto literario (Coloquio. Abril de 1986), ed. Jean-Pierre Étienvre y Leonardo Romero (Zaragoza: Casa de VelázquezUniversidad de Zaragoza, 1988), 11-24; Florence Serrano, "The Trésor des livres d'Amadis as an
} 
Amadís y sus descendientes son capaces de hablar muchas lenguas, son hábiles músicos y poetas. Como en la obra de Castiglione, también para los libros de Amadís el arte de la conversación es practicado y elogiado por sus efectos civilizadores: de su estructura narrativa, de sus motivos y personajes emana el mensaje de ejemplaridad, la gracia del caballero. A este propósito quiero fijarme en dos casos de representación de la corte en dos libros de caballerías, uno español y otro italiano, al comienzo y al final del recorrido del ciclo de los Amadises: unas páginas de Los cuatro libros de Amadís de Gaula de Garci Rodríguez de Montalvo, texto anterior al 1508; y unos capítulos del Esferamundi de Grecia de Mambrino Roseo da Fabriano, última obra de la serie (1558-1565). Del primer ejemplo me interesa destacar la gracia en la conversación cortesana, del segundo la fiesta continuamente renovada en ocasión del viaje de un séquito real. Pero antes de abordar estos ejemplos, me interesa recordar las palabras usadas por Amedeo Quondam en su introducción al Libro del Cortegiano, para definir conceptos importantes en la percepción de este modelo occidental de larga duración.

En primer lugar, Quondam subraya que lo que pasa entre los cortesanos reunidos en el palacio de Guidobaldo da Montefeltro en Urbino no es otra cosa que un juego fundado en la conversación: el juego de formar con palabras un perfecto cortesano. La construcción del modelo general se hace lúdicamente a través del diálogo, y se basa en la enunciación de esa regla universal que se resume en huir de la afectación y usar «in ogni cosa una certa sprezzatura che nasconda l'arte e dimostri ciò che si fa e si dice, venir fatto senza fatica e quasi senza pensarvi». En palabras de Quondam, la «regola universalissima della grazia» representa el núcleo organizador de todo el campo semántico del que derivan todas las prácticas de las relaciones sociales del sistema de la Corte, las diferentes «gracias» en el hablar, el vestirse, el moverse, el bailar, el comer. La gracia es, por tanto, el elemento común que homologa todas las actividades de esta práctica cortesana ${ }^{5}$.

Veamos entonces cómo se compone esta imagen. La verdadera profesión del cortesano es el ejercicio de las armas, que requiere cualidades físicas (la apostura del cuerpo, la gallardía y agilidad en los torneos, en las justas, en la guerra, etc.) pero necesita también de buen juicio. Además, son necesarias las letras, que equilibran las armas: en el espacio de la corte se concilian las dos prácticas separadas en los estatutos del laico y del clérigo. Por tanto, la corte es el espacio donde una cultura expresa su hegemonía, integrando todas las prácticas pertinentes a la producción de sus relaciones sociales; el único lugar donde es posible, bajo el signo de la gracia, tornear, bailar, jugar, conversar, montar a caballo y manejar todo tipo de armas, escribir, hacer música, pintar, etc. La regla de la gracia se despliega sobre todo en la

Anthology of Speeches", en Anthologies of Historiographical Speeches from Antiquity to Early Modern Times. Rearranging the Tesserae, dir. Juan Carlos Iglesias-Zoido y Victoria Pineda (Leiden-Boston: Brill, 2017), 357-378.

${ }^{5} \mathrm{La}$ «gracia», la «sprezzatura», implica evitar la afectación, que revelaría el esfuerzo y la fatiga; hay que encubrir el esfuerzo encontrando otra naturalidad, en equilibrio entre ocultar y aparecer, entre simulación y representación. El buen juicio integra la "gracia»: es un dispositivo mediador que permite alejarse tanto del esfuerzo como del arte (que caería en la afectación). Quondam, "Introduzione", XVI. 
conversación, en la que debe primar el sentido de la situación y de la conveniencia; conversar ante los ojos de los demás cortesanos es una forma de espectáculo, como las justas, el torneo o el baile y la música. La cultura de la corte se compone de «piacevoli feste e musiche e danze, nonché in belle questioni, in giochi ingegnosi e pronti detti» ${ }^{6}$. El cortesano debe dominar los motes, bromas y chistes, que constituyen además una práctica de gran importancia intelectual, porque de ellos resulta la agudeza, el ingenio y prontitud de quienes proponen y responden; por eso surge una retórica de la facecia, siempre en cumplimiento de la regla de la gracia, de la conveniencia, de la decencia y de lo moralmente irreprochable.

Obviamente, para Castiglione el papel de la mujer y del amor es fundamental, siempre bajo el signo de la teatralidad. El aspecto físico, la belleza y el atavío son esenciales ante los ojos del público; y sobre todo saber escuchar y responder: como subraya Quondam, más que ser el sujeto de la enunciación, las mujeres son el destinatario de todos estos ejercicios elaborados con gracia. Evidentemente el ojo que mira, el oído que escucha, es muchas veces femenino: el baile, el canto, la música, los versos están dirigidos a mujeres y la respuesta de la mujer debe ser adecuada, dotada de discreción, prudencia, disimulo en un complejo juego de verdad o falsedad, de teatro, de apariencia. El cortejo, la seducción, es una representación, un entrelazamiento de palabras, gestos, miradas orientadas funcionalmente a persuadir al amado.

En suma, la virtud del cortesano se expresa a través de acciones concretas, que son las actividades posibles en el cronotopo de la corte, como «far conviti magnifici, feste, giochi, spettacoli pubblici, avere numero di cavalli eccellenti per utilità nella guerra e per diletto nella pace, falconi, cani e tutte le altre cose che si appartengono ai piaceri dei grandi signori dei popoli e ancora fare magnifici edifici» ${ }^{7}$.

Si volvemos ahora a los libros de caballerías españoles, se puede afirmar que, en la caballería de papel, el cronotopo de la corte se presenta articulado en un abanico de actividades que dependen tanto de la tradición literaria como de la frecuentación de la práctica histórica coeva. Una investigación sistemática sobre los primeros cuatro libros fundadores (Amadis, Esplandian, Palmerín y Primaleón) me permitió proponer un discurso crítico sobre su adhesión o desviación del esquema artúrico, que enlaza el espacio de la corte y el de la aventura en una relación sumamente entrelazada ${ }^{8}$.

Según este esquema, las actividades de la corte durante los momentos de ocio y pasatiempo forman un repertorio de motivos literarios recurrentes. Se podría ofrecer un listado de las actividades representadas en libros de caballerías. Ante todo,

\footnotetext{
${ }^{6} \mathrm{El}$ cortesano debe ser ingenioso, discreto y gracioso; su competencia discursiva tiene la finalidad de «ricreare gli animi degli auditori indurli a festa e riso». Ver Quondam, "Introduzione", XVIII-XXII.

7 Ibídem, XXVII.

${ }^{8}$ Remito a Anna Bognolo, La finzione rinnovata. Meraviglioso, corte e avventura nel romanzo cavalleresco del primo Cinquecento spagnolo (Pisa: ETS, 1997), 75 y ss. La relación de interdependencia entre corte y aventura, que idealiza el ansia de integración política entre la grande y la pequeña nobleza feudal, fue teorizada por Erich Köhler, La aventura caballeresca. Ideal y realidad en la narrativa cortés (Barcelona: Sirmio, 1990).
} 
la conversación: la corte dialoga con agudeza, con intercambio ameno de motes, facecias, cuentos. Consecuentemente, los juegos de palabras y los juegos de ingenio y de sociedad, en los que la corte propone y resuelve cuestiones, problemas filosóficos. Sobre todo, la fiesta: la corte celebra banquetes, cenas y ameniza su ocio con las artes: poesía, música, danza y pintura. Especialmente, los espectáculos: representaciones teatrales, fiestas y ceremonias públicas, como entradas solemnes de cortejos reales, procesiones sagradas y profanas que movilizan ciudades enteras y todas las capas sociales, con ocasión de matrimonios, investiduras, coronaciones y sucesiones en el trono, de conversiones, bautismos y funerales. En las diferentes obras del género caballeresco, puede advertirse una acentuación hacia lo realista verosímil, o hacia lo artificioso maravilloso con efectos especiales sorprendentes. Los edificios que albergan la corte pueden encontrarse en un espacio urbano o en una residencia de campo, un castillo, una casa de placer; los palacios pueden ser decorados con estatuas y pinturas y circundados por bosques y jardines; consecuentemente la corte se dedica a paseos y a excursiones con visitas a las delicias naturales y artificiales: arboledas, flores, fuentes, juegos de agua, estatuas, autómatas. En la corte se alimentan y se cumplen los amores: amores furtivos, matrimonios secretos y matrimonios públicos. Por otro lado, en la fiesta de corte no puede faltar el deporte guerrero, este antiguo juego cruel: torneos, justas, pasos de armas, cabalgadas, donde lucir empresas, invenciones, divisas de los caballeros con todos sus significados de mensajes intratextuales y extratextuales heráldicos y simbólicos, conectado con formas poéticas del Siglo de Oro, sin olvidar las prendas y sobreseñales concedidas por las damas. El caballero puede esconder su identidad, tiene que ser ingenioso como discreto y manejar con la misma habilidad las armas y las letras. Una alternativa al alarde caballeresco de justas y torneos es el deporte aristocrático y violento de la caza. Esta dilatada fenomenología de situaciones cortesanas, que parece un listado poco ordenado, en las novelas caballerescas se entrelaza y se funde en una imagen orgánica y unitaria: lo que Quondam ha llamado la «forma del vivere» del caballero ejemplar.

Vamos ahora al análisis del primero de los ejemplos que quiero traer a colación, el arte de la conversación en el Amadís de Gaula.

Después de la aventura en la Ínsula del Diablo donde Amadís mata al Endriago, el emperador le recibe en Constantinopla con una feliz ceremonia. Amadís no puede ocultar su tristeza por la lejanía de su amada Oriana; cuando la joven hija del emperador le inquiere indiscretamente sobre su secreto sufrimiento amoroso, Amadís es capaz de contestar con gracia perfecta, con una doble verdad que resulta muy cortés y a la vez sincera. Me interesa destacar esta conversación con Leonorina de Constantinopla como un ejemplo del manejo del discurso cortesano por parte de Amadís, en un diálogo ejemplar delante de la corte más importante de la cristiandad.

Cuando ve aparecer a la hermosa niña, Amadís tiene un momento de conmoción al acordarse de Oriana. El emperador lo nota y toda la corte siente curiosidad por saber cómo «un caballero tan esforzado, tan discreto había mostrado tanta flaqueza ante el emperador y la emperatriz». Habiendo preguntado inútilmente al sabio Maestro Elisabat, acompañador de Amadís, el emperador, pensando que 
podría tratarse de un problema de amor, dice secretamente a su hija unas palabras. Entonces la princesa Leonorina pide públicamente tres dones en blanco al caballero que, de rodillas ante ella mientras la corte entera le está mirando, promete cumplir. El primer don es enviar «una hermosa corona [...] a la más hermosa doncella». El segundo don es dar una corona de «perlas y piedras de muy gran valor [...] a la más hermosa dueña». Antes de anunciar el tercer don, Leonorina quiere saber qué hará Amadís con las coronas. La cortesía, la galantería y el homenaje del caballero se hacen evidentes cuando pone la primera corona en la cabeza de la niña, diciendo: «Yo pongo esta corona en la cabeza de la más hermosa doncella que yo agora sé; y si oviere alguno que lo contrario dixere, yo se lo faré conocer por armas». La corte se alegra y Leonorina se sonroja.

Es a propósito del tercer don cuando se hace patente la habilidad de Amadís para salir de apuros en la conversación. La niña pregunta sin rodeos por «la razón por qué llorastes y quién es aquella que ha tan gran señorío sobre vos y sobre vuestro coraçón». El caballero, turbado, pide que cambie la demanda por otra más a su servicio, pero la princesa insiste impertérrita. Después de haberlo pensado, Amadís, con semblante alegre, contesta: «Mi señora, pues por ál no me puedo quitar de mi promesa, digo que, cuando aquí primero entrastes y vos miré, acordéme de la edad y del tiempo en que ahora sois, y vínome al corazón una remembranza de otro tal tiempo en que ya fue bueno y sabroso, tal, que haviéndole ya pasado, me hizo llorar como vistes». Pero no es suficiente: la niña quiere saber «quién es aquella por quien se manda vuestro corazón». El caballero tiene que sortear la dificultad y utiliza un discurso de doble sentido, que dice la verdad sin descubrir su secreto:

La vuestra gran mesura -dijo él- que a ninguno falleció, es contra mí. Esto hace mi gran desdicha; y pues que más no puedo, conviene que contra mi placer lo diga. Sabed, señora, que aquella que yo más amo es la misma a quien vos enviáis la corona, que a mi cuidar es la más hermosa dueña de cuantas yo vi, y aún creo que de cuantas en el mundo hay. Y por Dios, señora, no queráis de mí saber más, pues que soy quito de mi promesa9.

El emperador y la corte comprenden bien la situación: el don ha sido cumplido sin aportar la información deseada: «Quito sois - dijo el emperador- mas por tal guisa que no sabemos más que ante». El caballero no puede conceder más y la escena termina en paz y en bromas: al emperador, que le pide perdón por la indiscreción de la hija, Amadís responde que no perdonará tan pronto, porque la niña lo hizo provocada por sus padres; el emperador se ríe y comenta: «En todo os hizo Dios acabado», es decir: tan bueno en armas como en habla y cortesía. Y admite: «[...] quiero corregir lo suyo y lo mío [...]». Entonces Amadís besa las manos al emperador y promete tomar la enmienda en un futuro, cuando el emperador «esté

${ }^{9}$ Garci Rodríguez de Montalvo, Amadís de Gaula, ed. Juan Manuel Cacho Blecua (Madrid: Cátedra,

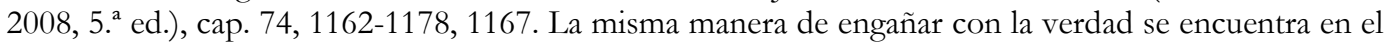
cap. 57, donde Beltenebros y Oriana superan brillantemente la prueba de la espada y la guirnalda de flores traída por el escudero Macandón. 
más descuidado», donde es transparente el doble sentido irónico, bélico-humorístico. El narrador concluye: «Estas palabras passaron entre aquel Emperador y el de la Verde Espada cuasi como un juego, mas tiempo vino qu'el efecto dellas salió en gran hecho, como en el cuarto libro desta historia será contado». El comportamiento cortesano de Amadís exhibe, pues, la propuesta de un caballero ejemplar, que sabe obrar tan bien en las armas como en la conversación, en el amor y en las buenas maneras, capaz de salir de apuros sin revelar sus secretos, sin ofender a tan altos huéspedes, bromeando con ellos.

Como acabamos de ver, la cortesía y la capacidad de actuar adecuadamente en una corte, se presentan ya en el Amadís de Gaula, el texto fundador del género. La escritura de Montalvo se remonta a la época de los Reyes Católicos, anterior a la redacción de El cortesano; sin embargo, evidentemente en la corte humanista de Isabel y Fernando esta forma de vivir ya se anunciaba. Pasando a la época del Renacimiento maduro, quiero traer a colación un episodio de corte itinerante, una cabalgata en una secuencia, un itinerario progresivo con recibimientos mágicos al final de cada jornada de viaje, que se encuentra en último libro de la serie, escrito en italiano, el Esferamundi de Grecia, una enorme novela en seis tomos (1558-1565) que tuvo un éxito europeo deslumbrante ${ }^{10}$. Es útil aquí una premisa sobre el protagonismo del Amadís en las fiestas de la realidad, limitando la consideración a España e Italia. Debemos a Stefano Neri unas densas páginas que recogen unas muestras de las fiestas italianas que aprovechan episodios de libros de caballerías españoles, como las de 1561 en el Palacio Ducal de Mantua en ocasión del matrimonio de Guglielmo Gonzaga y Eleonora de Austria (cuando se construyó un aparato que representaba la Ínsula firme, la Cámara defendida y el Arco de los Leales Amadores con una escenografía de Leone Leoni) o como la justa de Módena durante el carnaval de 1569 o como las famosas Cavalerie della città di Ferrara. Así el universo de la corte juega con los libros de caballerías, que a su vez se basan en un retrato de la sociedad de corte, en un círculo de imágenes, un reflejo recíproco, entre la caballería de la realidad y la caballería de papel $^{11}$.

${ }^{10}$ Sobre el Esferamundi de Grecia, ver Anna Bognolo, Giovanni Cara y Stefano Neri, Repertorio delle continuazioni italiane ai romanzi cavallereschi spagnoli. Ciclo di "Amadis di Gaula" (Roma: Bulzoni, 2013), que ofrece una información completa. Mucho material al respecto se puede consultar en el portal del Progetto Mambrino, www.mambrino.it [fecha de consulta: 4/5/2021].

${ }^{11}$ Stefano Neri, "Conversazioni, giochi, feste e commedie", en Anna Bognolo, Giovanni Cara y Stefano Neri, Repertorio delle continuazioni italiane ai romanzi cavallereschi spagnoli. Ciclo di "Amadis di Gaula" (Roma: Bulzoni, 2013), 128-139. Los estudios sobre el fasto cortesano han demostrado la relación que se estableció desde el siglo XV entre la narrativa caballeresca y las manifestaciones festivas de los estamentos aristocráticos: la caballería se convierte en juego y teatro que alimenta la ficción y a su vez las celebraciones cortesanas se inspiran en ella. La bibliografía sobre las fiestas es muy abundante; estudios ya clásicos son los de Francisco López Estrada, "Fiestas y literatura en los Siglos de Oro: la Edad Media como asunto 'festivo' (el caso del Quijote)", Bulletin Hispanique 84 (1982): 291-327, https://doi.org/10.3406/hispa.1982.4475; Daniel Devoto, "Folklore y política en el Castillo Tenebroso", en Textos y contextos (Madrid: Gredos, 1974), 202-241. Entre las referencias fundamentales, Teresa Ferrer Valls, La práctica escénica cortesana: de la época del Emperador a la de Felipe III (Londres: Tamesis, 1991) y Nobleza y espectáculo teatral (1535-1622) (Valencia: UNED, 1993); Jimena Gamba Corradine, Fiesta caballeresca en el Siglo de Oro. Estudio, edición, antología y catálogo (Zaragoza: Institución 
Veamos pues el segundo texto, los capítulos que van del 112 al 138 de la Tercera parte del Esferamundi de Grecia (1563) donde asistimos a una fiesta en la corte del rey de Palomaro, seguida por la aventura del Valle de Amor ${ }^{12}$. Al comienzo, la corte está celebrando una boda: en los torneos participan caballeros andantes de reinos cercanos. Nobles y villanos, ciudadanos y extranjeros acuden a la ciudad. Cada noche el rey determina qué campeones lucharán el día siguiente. Las damas visten ropas preciosas y regalan prendas de amor a sus caballeros para que las lleven en el combate. Cada día está marcado por etapas fijas: la misa, la conversación en el jardín, la justa por la tarde; la cena, los diálogos a solas con las doncellas amadas, los bailes por la noche. El héroe principal Astrapolo obviamente derrota a los contendientes y es proclamado ganador (cap. 117).

El episodio que me interesa destacar empieza mientras las princesas están sentadas en un mirador. De repente, el cielo se oscurece y todos los presentes se desmayan; cuando vuelven en sí, en lugar de la tribuna ha aparecido un castillo transparente que aprisiona a las doncellas, custodiado por tres gigantes. Los caballeros asaltan el castillo luchando contra los gigantes. Finalmente, la tierra tiembla y se difunde una espesa niebla: cuando se aclara, en medio de dulce música,

Fernando el Católico, 2017); en general Braden Frieder, Chivalry \& the Perfect Prince. Tournaments, Art, and Armor at the Spanish Habsburg Court (Kirksville: Truman State University Press, 2008); Helen Watanabe-O'Kelly and Anne Simon, Festivals and Ceremonies. A Bibliography of Works Relating to Court, Civic and Religious Festivals in Europe, 1500-1800 (Londres-Nueva York: Mansell, 2000); Helen Watanabe-O'Kelly, Margaret Shewring, James Ronald Mulryne, Sarah Knight y Elizabeth Goldring, Europa Triumphans. Court and Civic Festivals in Early Modern Europe (Londres: MHRA, 2004); y la base de datos Early Modern Festival Books Database de la University of Oxford, https://festivals.mml.ox.ac.uk/in dex.php?page=home [fecha de consulta: 4/5/2021]. Para España, la base de datos sobre Relaciones de sucesos de Biblioteca Digital Siglo de Oro (BIDISO) del Seminario Interdisciplinar para el Estudio de la Literatura Áurea Española (SIELAE) de la Universidade da Coruña, https://www.bidiso.es/Relaciones/ [fecha de consulta: 4/5/2021]. Sobre fiestas del siglo XVI especialmente Visiones de un imperio en fiesta, ed. Inmaculada Rodríguez Moya y Víctor Mínguez Cornelles (Madrid: Fundación Carlos Amberes, 2016); Claudia Demattè y Alberto del Río Nogueras, "El escultor Leone Leoni diseña la Ínsula Firme según las reglas de Serlio en las bodas del marqués de Mantua (1561)", en La invención de las noticias. Las relaciones de sucesos entre la literatura y la información (siglos XVI-XVIII), ed. Giovanni Ciappelli y Valentina Nider (Trento: Università degli Studi di Trento, 2017), 829-842. Sobre libros de caballerías Sylvia Roubaud, "Les fêtes dans les romans de chevalerie hispanique", en Les fêtes de la Renaissance. III, ed. Jean Jacquot (París: CNRS, 1975), 313-340; M. ${ }^{a}$ Luzdivina Cuesta Torre, "Fiestas de boda en (algunos) libros de caballería", en Actas del VIII Congreso Internacional de la Asociación Hispánica de Literatura Medieval, ed. Margarita Freixas, Silvia Iriso y Laura Fernández (Santander: Consejería de Cultura del Gobierno de Cantabria-Asociación Hispánica de Literatura Medieval, 2000), 618-630; Alberto del Río Nogueras, "En el principio fue el desfile. Entretenimiento cortesano y fastos ciudadanos en los libros de caballerías del primer tercio del siglo XVI", en El teatro en tiempos de Isabel y Juana (1474-1517), ed. Felipe B. Pedraza Jiménez (Cuenca: Universidad de Castilla-La Mancha, 2017), 73-93; Nieves Pena Sueiro, "Los casamientos del príncipe Felipe de Austria y María Manuela de Portugal en las relaciones de sucesos", en Festina Lente. Augusta empresa correr a espacio. Studia in honorem Sagrario López Poza, ed. Nieves Pena Sueiro y Carlota Cristina Fernández Travieso (La Coruña: Universidade da Coruña-BIDISO, 2019), 247-262.

${ }^{12}$ La terza parte dell'bistoria dello inuitissimo principe Sferamundi di Grecia nuouamente ritrouata, \& ridotta nella lingua italiana, per M. Mambrino Roseo da Fabriano (Venecia: Michele Tramezzino, 1563). Transcribo del ejemplar digitalizado en línea de la Biblioteca Nacional de Viena (40.J.16 [Vol. 20]). 
las princesas salen salvas del castillo cristalino, seguidas por los magos que habían realizado el encantamiento. No pasará desapercibido aquí el parecido con ciertas representaciones de fiestas como las de Binche en honor de Felipe II, o las antes apuntadas de Mantua, de Milán o de Ferrara ${ }^{13}$.

Los magos advierten que la boda debe posponerse: antes hay que liberar al príncipe de Palomaro, víctima del encantamiento del Valle de Amor, donde una maga enamorada lo ha encerrado. Los caballeros protagonistas y sus amadas parten en una "gran cavalcata in gran piacere e solazzo» con la reina de Palomaro y su séquito $^{14}$.

Hay que subrayar que la narración está siempre focalizada desde el punto de vista de los príncipes y el lector sabe solamente lo que perciben ellos, de manera que su maravilla también es la maravilla del lector. Ya en el título del cap. 125 se pone al lector sobre aviso, anunciando una burla ${ }^{15}$. Cuando la compañía llega al alojamiento previsto «presso una piacevol riviera», encuentra unas tiendas extrañas «tutte di tela di oro in numero di più di trecento, e tanto alte che pareva che toccassero le nuvole; fra l'una e l'altra tenda [...] si vedevano tanti frascati ornati di rose e viole così ben ordinati e sì ben contesti che pareva che quivi fossero stati mastri un anno in buon numero a lavorargli». La maravilla aumenta al ver que a recibirles vienen cien doncellas y cien jóvenes misteriosos de piel negra: «[...] una schiera di donzelle more ricchissimamente vestite [...] cantando con leuti, flauti e altri instrumenti, ed eran le voci sì sonore e melodiose che se molto fossero durate avrebbono avuto nelle dame e ne' cavallieri quella forza che hanno nel lor canto le sirene». Dentro de las tiendas hay «altri piccioli padiglioni con letti di finissimi lavori, e tanti vasi e credenze di oro e di argento che dieci re non ne aveano altretanti». A la hora de la cena, aunque sus criados no aparecen, el servicio es perfecto: debajo de «un grande e spazioso frascato, ove una soave aura della riviera vi dava» aparece «un'altra superba credenza di vasi di oro e di argento, e le tavole erano coperte di finissime nappe. Eran quivi seggie

${ }^{13}$ Juan Cristóbal Calvete de Estrella, El felicíssimo viaje del muy alto y muy poderoso Príncipe don Phelippe, ed. Paloma Cuenca (Madrid: Sociedad Estatal para la Conmemoración de los Centenarios de Felipe II y Carlos V, 2001); Alberto del Río Nogueras, "Motivos folclóricos y espectáculo caballeresco: el príncipe Felipe en las fiestas de Binche en 1549", Revista de Poética Medieval 26 (2012): 285-302, https://doi.org/10.37536/RPM.2012.26.0.30676; Lilia Elda Ferrario de Orduna, "Sobre El felicissimo viaje de Calvete de Estrella: una poética de las entradas reales. Ficción y realidad", Anuario de Letras 35 (1997): 461-487; sobre torneos y celebraciones caballerescas en Ferrara en 1561-1570, cfr. Guido Baldassarri, "Cavalerie della città di Ferrara", Schifanoia 1 (1986): 100-125; Jimena Gamba Corradine, Caballería, diplomacia y ficción entre España e Italia: "El Monte de Feronia" (1563) (Salamanca: Universidad de Salamanca, 2016). Todos los viajes de la realeza eran ocasión de agasajo y fiesta no solamente en entradas, sino durante el camino. Un ejemplo más: el viaje de Felipe II para casarse con María Tudor en Inglaterra en 1554 fue celebrado en los dominios del duque de Benavente; cfr. Teresa Ferrer Valls en Nobleza y espectáculo teatral, 177 y ss.

${ }^{14}$ La reina «avea molto caro questo viaggio perché avrebbon avuto più passatempi che con lo star fermi in quella città [...]. Risolverono di alloggiar in campagna più tosto che in città alcuna e perciò conducevano con loro molti camelli e dromedarii che portavan loro le credenze, le cucine, e le doppie tende, che mentre facevano uno alloggiamento, i ministri apparecchiavan l'altro della sera del giorno seguente» (f. 418r). Las cursivas son siempre mías.

15 «La burla che fu fatta a questa regal compagnia nello alloggiamento della prima sera». 
ricchissime coperte di varii drappi recamati di oro, e finalmente si vedeva pompa tale che tre ricchi imperatori uniti insieme non avrebbon potuto mostrar maggior ricchezza». Los nobles huéspedes son muy bien servidos y comentan «questa gran magnificenza e inestimabile apparato che avean trovato quivi, della ricchezza delle tende, delle sontuose e delicate vivande e preziosi vini, del polito servire, de' ricchissimi e infiniti vasi di oro, e finalmente della leggiadria e gran beltà di quelle donzelle more». La noche se ilumina gracias a «ricchissimi candelieri di oro e di argento in gran numero sopra le tavole con grossi cirii di cera bianca». Al amanecer, se escucha «una musica sì eccellente e melodiosa che così pose in estasi gli animi di tutti come se avessero udito un concento di angeli cantare». Los príncipes, agradecidos y maravillados, se despiden con palabras «di cortesia e di creanza» sin poder averiguar la identidad de sus misteriosos huéspedes ${ }^{16}$. La opulencia del recibimento, su extrañeza y su exotismo no podrían ser mayores.

La segunda noche (cap. 126) la comitiva se aloja en un castillo conocido que, sin embargo, se ha trasformando totalmente: «[...] la porta [...] si era posta dalla contraria parte, e la muraglia [...] era fabricata di mattoni di bronzo in forma di diamanti in punta, che vi erano quattro gran torri che pareva che giongessero al cielo, sopra le quali erano quattro soli sì risplendenti che pareva che togliessero lo splendore al sole [...]». La reina pregunta al señor del lugar «chi sia stato questo eccellentissimo mastro» que hizo tal magnífica reforma. Su vasallo confiesa que, mientras se preparaba para recibirlos, había llegado «un nobil cavalliere con una nobil donna», que pronto desaparecieron, dejando «cose di tanto stupore quanto si potessero vedere, che vedemmo nella piazza un castello di nuovo fabricato con quelli ornamenti che ora vedrete voi [...] a oro in musaico [e] opre tanto eccellenti, che ben stupirete di esse».

En el patio de armas hay un castillo más pequeño «tutto coperto di tela di oro e di argento di maraviglioso lavoro» (caps. 127 y 128). Hermosas doncellas defienden las murallas lanzando frutas, flores y esencias perfumadas. Entre las almenas, grandes espejos permiten que los huéspedes se admiren a sí mismos. Sobre las torres vuelan banderas con la insignia del dios del amor. Una inscripción colocada en una columna de oro declara: «Questa è la Rocca di Amore nella quale son vinti i vincitori che la prendono». Al redoble de los tambores, cincuenta jóvenes con armaduras doradas asaltan la fortaleza, mientras las doncellas la defienden tirando naranjas y frutos perfumados. Al caer de la noche, llegan escuderos con antorchas brillantes y comienza un nuevo asalto: de los muros del castillo llueven rayos que, golpeando a los príncipes y princesas, iluminan sus corazones con intensa pasión. Cuando la fortaleza es conquistada, salen las doncellas guardianas acompañadas de la mano de los jóvenes aventureros. A la mañana siguiente, la Rocca d'Amore ha desaparecido y el castillo ha vuelto a su forma original: todas las maravillas eran obras de magia.

Merece la pena transcribir una breve muestra del contenido de estos capítulos. En las almenas, «bellissime donzelle con corone di oro in testa, e bellissime

\footnotetext{
${ }_{16}$ «Ma la maraviglia che era nella reina e in tutte sopra chi potesser esser quelle donzelle, e donde fossero venute, di che non si potevan dar pace, varie cose di esse imaginandosi e in niuna accertando».
} 
ghirlande con capegli all'aura per le spalle sparsi» tienen arcos y flechas ensartados de «cedri, aranci, limoni, e altri pomi di grande odore, palle di muschio e di ambra coperte di rose e di viole». Tienen jabalinas «di canne di zuccaro tutte dorate» y espejos decorados. Las banderas de las torres son «di porpora nelle quali era dipinto il Dio d'amore con la faretra, ignudo, nel modo che lo descrivono i poeti». Mirándose en los espejos, las princesas «di soppremo piacere dubitavano che non gli intravenisse quel che a Narciso avvenne, di innamorarsi di se stesse». Los cinquenta aventureros que, anunciados por tambores, irrumpen en el castillo «per dar spasso alla reina e a quelle principesse e nobili cavallieri» y asisten desde las ventanas al «bello e gentil spettacolo», visten «arme tutte bianche dorate che lor parevan dipinte indosso [...] con penacchi di varii colori in cima, portavano picche di una forte pasta composte, che rendevano un mirabilissimo odore e per punta aveano anco essi aranci e cedri e variati pomi, e molti ne portavano in duo carri dietro per tirargli alle donzelle all'alto». El combate-espectáculo, interrumpido por una cena a manera de descanso, se desarrolla así:

Erano in altri carri condotte scale dipinte di varii colori con archi e frezze nel medesimo modo che avean le donzelle ne' merli. Fermatasi questa piccola battaglia [...], a un tempo si misero tutti in punto per dar l'assalto, e le donzelle disopra si misero le lor celate o sottili elmi in testa e al petto ponendosi gli scudi [...]. Compartiti i pedoni, cominciarono a dar un dei bene ordinati assalti [...] che alcuni cercavan con il tirare delle frizze levar le diffensore donzelle dai merli, e altri appoggiavano alle mura le scale per sallir disopra. [...] In un momento se ne vidde piena la piazza ed era così bello spettacolo à riguardanti che di gran tempo non ebbero piacer che a questo si uguagliasse. Durò questo assalto una grossa ora, nel quale i donzelli armati si mostraron molto destri e valorosi, e le donzelle si difendevano con sì bel modo che era un gran passatempo il vederle. Ma perché in questo tempo era l'ora della cena e le vivande si guastavano, sonaro i tamburi alla ritirata, e alora si vidde riunirsi gli assalitori con tanto bell'ordine e riporsi in battaglia [...]. Parve che avessero questi giovani combattenti veduto il comparir degli scalchi con le vivande in tavola, così appostarono di far la ritirata a tempo, come se avessero detto che non era onesto di far raffredar quelle vivande e impedir il tempo della cena. E se ne usciron con bella ordinanza fuor della piazza a suono dei medesimi tamburi, e dentro il castello fecero le donzelle assediate gran festa di aver ributtato i nemici con suoni di arpe, arpicordi, leuti, flauti, e altri simili instrumenti cantandovi con tanta melodia, che mentre la reina e le dame tutte con quei principi mangiavano, non ardivan di parlare, così erano intenti in ascoltarla.

La música dura todo el tiempo de la cena «sempre variandola le donzelle con nuovi concenti»; después empieza el segundo asalto, anunciado por los tambores: «onde tutte con gran contentezza si rimisero alle finestre, ed ecco i giovani comparir con altre armi smaltate di color verde con gentilissimo modo nella spaziosa piazza»:

Questo assalto durò tanto che venne la notte oscura, e alora si viddero comparir cinquanta scudieri pomposamente vestiti per una strada con due torce grosse di cera bianca nelle mani per ciascuno, schierandosi in luogo con che potessero ben 
illuminar la festa, e fu cosa di maraviglia che una di queste torce sole dava tanto lume quanto ne avrebbon dato cento torce ordinarie. [Cap. 128] Fecero questi cinquanta giovani armati una mirabil mostra di loro passando sotto le finestre della reina e delle principesse con la insegna spiegata, e facendo lor riverenza nel passare. Dopo di nuovo si rimisero allo assalto del castello, ma con più bello ordine e miglior apparecchio per espugnare quelle mura [...]. Eran gli occhi dei riguardanti sì invaghiti nel mirar si bello spettacolo che non ardivan di pur respirare. Le vaghe e valorose donzelle dall'alto scoccando frizze di quelli odoriferi pomi, e gittando [...] sopra i lor amati avversarii gran quantità di rose, gigli e viole, talora gli coprivan in modo che eran essi forzati di ritirarsi dallo assalto, e quando si ritiravano di dentro in segno di vittoria si udivan musiche molto soavi [...]. Sventolava le insegne di amore, e ad ora ad ora si disserravano alcuni raggi di fuoghi che [...] in cambio di lasciar puzza di polvere, lasciavan uno odore tanto soave che confortavano tutti, di tal sorte [...] che quel fuoco non abbrusciava, onde [...] colsero in seno [las princesas] così improvisamente che non ebbero tempo di ritirarsi adietro [...] ma quando sentivano quel soavissimo odore, e viddero che non gli abbrusciavan pur $\mathrm{i}$ veli che aveano adosso [...] se ne assicuraron in modo, che quando gli vedevano andar per aere, gli aspettavano con gran giocondità. [...] I raggi (poiché questo tutto avveniva per opra di Zireno e di Zirzea) [...] non coglievan se non quelli e quelle che si amavano con speranza di futuro matrimonio [...]. [Las doncellas] per più trattener quel giuoco, e più far penar gli assaltatori nell'amor loro, tal'ora gli refrigeravan [...] con quelle rose e viole che gli gittavano addosso [...] onde venivano a temperarsegli quegli amorosi fuochi [...]. Or questo amoroso assalto durò quattro ore con il più bello e lieto spettacolo che mai si vedesse, e in questo tempo le principesse e donzelle che non avean avuto il rifrescamento delle rose e viole si sentivan negli amori loro molto infiammati [...]. [Cuando los donceles entran] si sentì dentro una soavissima musica che durò un quarto d'ora così melodiosa e grata che indolcì maravigliosamente. Indi a poco si sentì là entro un strepito come di catene [...] si aperse una gran porta [...] e uscendo molte torcie accese portate da alcune donzelle, si vidde con stupenda mostra venir fuori le donzelle che avean difesa la rocca tanto armate di alcune arme del petto e delle spalle con i lor elmi in testa e con gli scudi al collo, con carcassi alla cintura e gli archi da una mano, succinte con tanta leggiadria che era cosa da indolcire ogni animo doglioso. Dalla man destra conduceva ciascuna di esse un dei giovani vincitori legato in una catena di oro, e in mezzo di questa schiera era una insegna, che una di queste belle donzelle portava, di color vermiglio con lettere intessute di oro che così dicevano: "Chi ardisce di entrar nella Rocca di amore, sia certo di esser vincendo vinto, che questa è la legge che ha Amor nel suo regno statuita". [...] Con questo trionfo se ne uscì della piazza questa compagnia allo splendor di quelle torcie, e le due principesse con l'altre dieci donzelle e i cavallieri si tolsero dalle finestre già che era vicina la mezzanotte $[. .$.$] e quando apparve la mattina [...] non viddero più né la rocca$ né vestigio che di essa vi fosse rimaso, e quel che le pose in maggior stupore, fu che il palaggio di quel signore e le muraglie del castello rimasero nella forma che furon da principio fabricate, essendo sparito tutto quello artificio che per opra di incantamento vi era stato aggionto.

El capítulo termina con los chistes por la desilusión del señor del lugar, que deduce que «questo fosse avvenuto per opra di incantamento». Es fácil notar el 
parecido con las fiestas aristocráticas antes recordadas; también me interesa evidenciar el léxico de la gracia cortesana usado por Roseo: sustantivos como spettacolo, passatempo, trionfo son las palabras clave que marcan el sentido del pasaje.

Cuando la compañía retoma su viaje, se oye un sonido de cuernos y ladridos de perros y salen del bosque gamos, ciervos, liebres y conejos (caps. 129 y 130). Los cazadores llaman a los perros, se dirigen hacia la reina e invitan a todos a quedarse con ellos. De unas cabañas sale una multitud de doncellas ataviadas de cazadoras, con el pelo suelto, botas rojas, vestidas de bermellón y morado. Las cazadoras acompañan a los invitados a las cabañas, que resultan ser alojamientos lujosos. La cena nocturna está iluminada por un pequeño sol mágico. En el cuarto día (cap. 131) la compañía asiste a una caza de animales salvajes: jabalíes, grandes ciervos, dos centauros armados con cimitarra. Después de la caza, el grupo almuerza cerca de una fuente, se despide de los cazadores y reanuda su viaje.

También estos capítulos merecen citarse. Cuando se acercan a los alojamientos, los protagonistas

sentirono gran quantità di corni, e abbaiar cani in una bella foresta vicina. [...] Ed ecco cominciarsi la bella caccia essendo da molti cacciatori circondata la picciola foresta, e [...] si viddero in un momento uscir fuor di essa da tutti i lati tanti piacevoli animali, daini, caprii, lepri, conigli di gran grandezzae bellezza. I cacciatori, lasciati i loro cani, seguiron gli animali che se ne venivano in gran schiera verso l'alto ove eran i principi e principesse, e quivi si vidde la più bella e graziosa caccia che mai si vedesse [...] ed era un miscuglio di cani e di questi animali involtati con loro sì grande, che spesso i cani nel voler qualche un di essi abboccare, abboccavan gli altri cani.

No puede faltar el motivo del amparo femenino:

Spesso occorreva che, or lepri, e or conigli non potendo più difendersi dai mordaci cani, saltavano in grembo a quelle dame lamentandosi, quasi domandandogli che lor campassero la vita [...] e le donne gli stringevano abbandonando le redini de' lor palafreni [...] ed era il ridere e il piacer grande di tutte, e massimamente che questi timidi animali spargevan così riscaldati un maraviglioso odore che le confortava tutte. [Hasta que] i cacciatori da basso richiamavano i loro cani con corni, ed eran quei suoni sì dolci che empievan di melodia le orecchie di quei cavallieri e dame, e ritirati i cani, tutti quegli animali venivano a inginocchiarsi a quelle principesse e nobil dame facendo atti di ringraziamenti che per causa loro fossero da quella gran furia de' loro avversarii salvati, di che si prendevano elle infinito trastullo.

Las viviendas de los cazadores son casas lujosas. De sus puertas sale

una schiera di belle e graziose donne cacciatrici a l'usanza delle nimfe di Diana nelle caccie antiche con archi al collo, e con faretre al lato, succinte con stivaletti di color vivo rosso, e con capelli a l'aura sparsi. Portavano vestimenti di color vermiglio di sotto e di sopra una cotta candidissima sì corta che faceva la bella veste di sotto apparirgli che era di 
una finissima purpura [...]. Queste leggiadre e belle cacciatrice raccolsero i principi e le principesse con gran cortesia non si saziando di onorarle e festeggiarle [...]. Ma quando elle entraron dentro le cappanne, viddero esservi stanze regale se ben tutte terrene, e così commode, che le fecero stupire. [Las bellas cazadoras] deposte le faretre e gli archi ad altro non si occupavano se non [...] in trattener le principesse e lor donne, e [...] in apparecchiar le tavole di fuor delle cappanne, e procurar la cena [...]. Essendo già notte furono accesi i lumi [y] sopra di esse tavole comparse un sole picciolo, ma di maraviglioso splendore che [...] illuminò come se fosse stato di mezzogiorno. [...] La cena fu solo di carne di variate selvaticine e così ben condite quanto in regal corte si potessero condire. Ebbero molti latticinii di varie sorti, e frutti sì eccellenti che parevano usciti di un paradiso terrestre.

La comitiva descansa gustosamente; al amanecer el sonido de cuernos invita a la segunda caza, de animales mayores:

Giunsero alla gran foresta che non era molto lontana, e con un maraviglioso ordine in un momento fu circondata dai cacciatori e cacciatrice da tutte le bande, ed era così ordinati che essendo il sito a guisa di un teatro, ma con poca pendenzia, le belle dame cacciatrici stavano più in dietro e più alte, e più bassi e più alla foresta vicini, i cacciatori. Aveano le dame un arco in mano e con la faretra piena di frizze molto ammaestrate. I cacciatori avevano duo dardi in mano [...] e uno spiedo forte e gagliardo per resistere alla furia delle terribile fiere, e portavano una picciola scimitarra al lato. Si sparsero le principesse e lor donne e donzelle in circuito per vedere, soprestando alle donne cacciatrici, ciascuna avendo al lato il suo cavalliere armato per tutto quel che fosse potuto avvenire [...].

Es evidente el lado espectacular del episodio cinegético, que procura trastullo, placer y maravilla: desde el circuito en forma de teatro, las nobles damas ven cazar cincuenta feroces jabalíes y «un numero infinito di cervi di stupenda grandezza e con corne grandissime e molto elevate» y al final asisten a la batalla más espantosa, con los «centauri di fierissima guardatura armati di pelle di draghi con due gran scimitarre nelle mani». Se trata de «una delle belle caccie, che si potessero vedere».

Ya se ha comentado cómo en las representaciones de los festejos españoles e italianos el escenario rústico (boschereccio) se alternaba al palaciego ${ }^{17}$. Hay que añadir que era usual ofrecer a los nobles obsequiados una sesión cinegética, como se ve claramente en la acogida que los duques reservan a don Quijote y Sancho (II, 30). Recordemos cuanto recalcaba Quondam a propósito de la virtud del cortesano, que debe expresarse en acciones concretas: no solo organizar magníficos banquetes, fiestas y espectáculos públicos, sino también deleitarse con la caza: poseer caballos, halcones, perros es parte de los placeres de los grandes señores. Finalmente, merece la pena seguir destacando el léxico de Roseo, o sea los predicados y atributos que declinan las particularidades de la gracia: la belleza, la cortesía, la dignidad, o también

${ }^{17}$ Como en las fiestas de bodas de Mantua en 1561 recordadas anteriormente, donde se alternan un escenario palaciego con uno rústico boschereccio. Cfr. Dematté y Del Río Nogueras, "El escultor Leone Leoni”, 839. En Madrid estas cacerías se solían organizar en El Pardo. Hay fiestas con episodios de caza en libros de caballerías, como en el Florindo, estudiado por Alberto del Río Nogueras. 
adjetivos como afable, amable, digno, noble, discreto, gentil, placentero: por ejemplo, encontramos la bella e graziosa caccia, la gentil caccia, $i$ tanti piacevoli animali, l'infinito trastullo, le belle dame cacciatrici. Más adelante encontraremos locuciones semejantes: la gran cortesia, il meraviglioso ordine, le belle pitture, i deliziosi giardini, le amene fontane, palagi ed edifici ricchi e sontuosi, $i$ dolci concenti; y constataremos los sentimientos que inevitablemente provocan: gran diletto, grande allegrezza e gioia dei cuori, meraviglioso piacere, gran trastullo, tutti i piaceri e le consolazioni, piacevolezza e molto riso.

Cada noche los viajeros encuentran maravillosos refugios. Sin saber dónde se alojará la noche siguiente, la comitiva llega a «un palagio in mezzo la campagna di tanta grandezza che pareva una picciola città» (cap. 132). Les espera una «bellissima matrona pomposamente vestita» acompañada por «alcuni onorati cavallieri [...], con certi nani innanzi lei, e dietro molte onorate donzelle tutte vestite di tela d'oro e tela d'argento». Al entrar, el palacio despliega toda su maravilla: un jardín rodeado de espaciosas galerías y cámaras decoradas de mosaico. Al subir las magníficas escaleras «fabricate di finissimi marmi», entran en la gran sala

[...] e viddero cosa di infinito stupore, che a l'un dei capi di essa risplendeva un picciol Sole di tanto splendore che abbarbagliando la vista di tutti, niun poteva gli occhi liberamente affissarvi, dall'altro lato contrario che era sulla entrata, risplendeva una Luna [...]. Dalli altri dui lati della spaziosa e ampia sala eran tutte figure di mosaico di stupendo lavoro, tutte di famosi eroi e cavallieri signalati con i successi delle cose loro, e tutte le battaglie successe nell'amor del famoso Amadis di Gaula con la sua bella Oriana, [...] l'historia dipinta de' gran fatti dello imperator Splandiano, [...] di Lisuarte di Grecia [,] [...] di Amadis di Grecia [,] [...] di don Florisello, [...] di don Rogello [...] Sotto il sole [...] era l'historia di don Silves, [...] ove era la luna era l'historia del principe Sferamundi di Grecia, con i suoi valorosi fatti e quei di Amadis d'Astra [...].

La sala mágica con paredes de mosaico representa la suma de las aventuras de la serie de Amadís. Se encuentran ambientes análogos en la tradición épica, artúrica o pastoril, donde abundan las salles aux images, las Casas de la Fama o los Templos de Amor, como la casa de la maga Felicia en la Diana de Montemayor ${ }^{18}$.

Los invitados quedan asombrados por tanta belleza. Vueltos a sus habitaciones, la señora los espera para cenar y, a la mañana siguiente, la comitiva pasea por deliciosos jardines y desayuna en «un'altra spaziosa sala terrena [con] sontuose e ricche imbandigioni». A este propósito, nunca se insistirá suficientemente en la importancia que los jardines asumieron en la primera Modernidad como espacios cortesanos alternativos al palacio señorial, lugares de ocio, de conversación,

18 Guido Baldassarri, "Ut poesis pictura: cicli figurativi nei poemi epici e cavallereschi”, in La corte e lo spazio: Ferrara estense, a cura di Giuseppe Papagno e Amedeo Quondam (Roma: Bulzoni, 1981). Remito a mis trabajos sobre estos capítulos del Esferamundi: "Il romanzo in una stanza. Le sale istoriate dello Sferamundi di Grecia", en Con gracia y agudeza. Studi offerti a Giuseppina Ledda, ed. Antonina Paba (Roma: Aracne, 2007), 85-104; "Los salones pintados de la Historia di Sferamundi di Grecia de Mambrino Roseo da Fabriano", en Il mondo cavalleresco tra immagine e testo, ed. Claudia Demattè (Trento: Università di Trento, 2010), 85-113. 
de festejos y de encuentro amoroso; es evidente, como otros libros de caballerías, la relación de intercambio mutuo con la realidad histórica ${ }^{19}$.

Mas tarde la señora los conduce a otro maravilloso palacio apartado como en una isla, donde los protagonistas, vencidos por un fuerte viento, no pueden entrar (cap. 133):

[...] un nobilissimo appartamento che era posto come in isola, sequestrato dalle altre stanze del palagio, e quando l'ebbero [...] ben rimirato di fuori, ella andò alla porta di esso e l'aperse e vi entrò, e chiamò la reina che entrasse dentro, il che fece ella, $e$ ridendo chiamò parimenti dopo le due principesse, le quali nel voler entrarvi furon respinte da un gran vento tanto che lor convenne di ritirarsi a dietro al loro mal grado; pregaron i duo principi che vi si provassero, e essi per ubbidirle lo fecero, e furon con non minor furia respinti, e quantunque facessero gran sforzo, non potevan sforzare la gran furia del vento che gli ributtava a dietro. Le due principesse, pigliandosi piacer di vedergli far quel grande sforzo indarno, scherzando gli dicevano: "- E che pensavate voi che per esser cavallieri più aveste potuto far di noi nel fatto di questa aventura? Essi si cacciarono a ridere, e la principessa Eliana ridendo molto disse alla signora del palagio: - Per mia fe - signora - che se non provedete che noi potiam là entro entrare, vedrete quel che noi faremo. $-E$ che farete voi se non vi entrate? - rispose ridendosi molto la savia donna. - Staremo di fuori, disse la principessa. Allora risero tutte, veduto massimamente la grazia con che ella ciò disse".

Al igual que la próxima aventura del Valle de Amor, la entrada está reservada a parejas casadas y, para que los héroes y sus enamoradas puedan ingresar en esta "cámara defendida" la reina decide que se celebren inmediatamente los matrimonios. Lo que me interesa subrayar es el aire lúdico y el tono risueño del episodio, que imita y supera, en agudeza y modernidad, la famosa prueba de la Ínsula Firme y otras de la caballería real y de papel: la típica ordalía amorosa de las novelas caballerescas se

\footnotetext{
${ }^{19}$ Los jardines caballerescos de Roseo se añaden a los jardines de papel estudiados por M. ${ }^{\text {a }}$ del Rosario Aguilar Perdomo, "La disposición escénica: algunas arquitecturas efímeras de los libros de caballerías españoles", en Destiempos.com. Caballerías (dossier), ed. Lillian von der Walde Moheno y Mariel Reinoso I., México: Grupo Destiempos, 23 (2009-2010): 69-103. Disponible en https://www.academi a.edu $/ 4807151 / \mathrm{La}$ disposici $\% \mathrm{C} 3 \% \mathrm{~B} 3 \mathrm{n}$ esc $\% \mathrm{C} 3 \% \mathrm{~A} 9$ nica algunas arquitecturas ef $\% \mathrm{C} 3 \% \mathrm{ADmeras}$ de los libros de caballer $\%$ C3\%ADas espa $\%$ C3\%B1oles [fecha de consulta: 4/5/2021]; “"Espesuras y teximientos de jazmines': Los jardines en los libros de caballerías españoles, entre lo medieval y lo renacentista", eHumanista. Journal of Iberian Studies 16 (2010): 195-220, https://www.ehumanista.ucsb.edu/sites/secure.lsit.ucsb.edu.span.d7 eh/files/sitefiles/ehumanista/v olume16/11\%20ehumanista\%2016.aguilar perdono.pdf [fecha de consulta: 4/5/2021]; "Jardín, fiesta y literatura caballeresca", en De cavaleiros e cavalarias. Por terras de Europa e Américas, ed. Lênia Márcia Mongelli (Sâo Paulo: Humanitas, 2012), 425-440; "El palacio fuera de palacio: prácticas arquitectónicas y festivas en jardines históricos y literarios de la temprana Edad Moderna", Anales de Historia del Arte 23, 2 (2013): 415-429, https://doi.org/10.5209/rev ANHA.2013.v23.42844; “Plantamos jardines y edificamos la habitación del Monte': prácticas arquitectónicas y jardineras de la nobleza española en la Edad Moderna. Aproximación a los vínculos entre destinatarios, sus jardines y los libros de caballerías", Historias Fingidas 2 (2014): 49-86, https://doi.org/10.13136/2284-2667/17. También Jesús Duce García, Antología de autómatas en los libros de caballerías castellanos (Alcalá de Henares: Universidad de Alcalá, 2016).
} 
desarrolla entre escaramuzas verbales, risas y bromas en el registro más hermoso y divertido de la burla cortesana ${ }^{20}$. También hay que subrayar que la gracias y donaires vienen de labios femeninos: los libros de Roseo, en el papel humorístico de las mujeres, reflejan un mundo cortesano más libre; las mujeres parecen desempeñar el rol faceto que Castiglione atribuye a la doncella de corte ${ }^{21}$.

El capítulo 134 representa entonces una defensa «della eccellenza del matrimonio» ${ }^{22}$ mientras en el 135 , celebrada su boda en una capilla, las parejas prueban con éxito la aventura del salón prohibido, donde su llama de amor se renueva en un ambiente afrodisiaco de perfumes y extática música. Por su interés, vuelvo a citar el texto:

[...] quasi il resto di quel giorno consumarono in acconciarsi per comparir leggiadre e belle nelle nozze, le quali la signora del palagio fece ordinar molto pompose e solenne. [...] Venuta l'ora furono sposati tutti e fu cominciata una solenne festa [...]. Venuta la mattina [...] tosto che salirono le scale di questo appartamento [...] sentì questa coppia una musica così soave $[. .$.$] e si sentiron così di amore infiammare che$ [...] si abbracciarono sentendo maraviglioso piacere. [...] Tosto che misero il piede in quelle stanze sentirono rinovarsi le amorose fiamme con assai maggior ardor di prima [...]. Struggevansi i duo amanti tanto nei loro desiderii amorosi che si sentivan dileguare i cuori loro, e si miravan con amorosa dolcezza [...].

Durante el día los enamorados se entretienen con cuentos de amor:

[...] con mille parole di gran trastullo si misero a trattener anco essi, perché fosse sino alla notte servato lo star soli insieme, [...] con quei grati ragionamenti se ne passavano il giorno, massimamente che sempre qualche una di quelle dame lor raccontava qualche caso

${ }^{20}$ Alberto del Río Nogueras, "Libros de caballerías y burlas cortesanas. Sobre algunos episodios del Cirongilio de Tracia y del Clarián de Landanís", en Literatura caballeresca entre España e Italia (del "Orlando" al "Quijote"), ed. Folke Gernert (Salamanca-Kiel: Seminario de Estudios Medievales y RenacentistasSociedad de Estudios Medievales y Renacentistas-CERES de la Universidad de Kiel, 2004), 53-65.

${ }^{21}$ Federica Zoppi, "Risa y mujer: motivos de humorismo femenino en el ciclo de los Palmerines", Historias Fingidas 8 (2020): 223-255, https://doi.org/10.13136/2284-2667/156.

${ }^{22} \mathrm{El}$ título del cap. 134 es como sigue: Gli essorti che diede questa gentil matrona nel maritarsi le donzelle e $i$ cavallieri, e le lodi che diede alle maritate e alli ammogliati. «La gentil signora del palagio [...] cominciò a lodare ed essaltar molto la eccellenza de' maritati e colligati in matrimonio, mostrando che era stato da Iddio ordinato, e dalla chiesa santa instituito, e come fra tutte le amicizie umane niuna era almondo più ferma e più fidata che quella dei congiugati, perché tutte l'altre eran quasi fallaci e non punto durabili». El discurso en defensa del matrimonio, que no es nada casual en la época del concilio tridentino, se puede comparar con el diálogo de instrucción de las doncellas que Feliciano de Silva incluyó en el Florisel de Niquea: José Julio Martín Romero, "El Ornamento de princesas: un diálogo sobre la educación femenina de Feliciano de Silva", Tirant. Butlletí informatiu i bibliogräfic de la literatura de cavalleries 10 (2007): s. p., http://parnaseo.uv.es/tirant/butlleti.10/art.romero feliciano.htm [fecha de consulta: 4/5/2021]. Es curiosa y puede parecer contradictoria la presencia de un sermoncito cristiano junto con un epitalamio gozoso y feliz. Roseo tiende evidentemente hacia una formación de compromiso. La noble protectora de Roseo, Clarice dell'Anguillara, se casó muy joven en 1560; no parece descaminado pensar que escribiese estos capítulos de consejos para casadas, uniendo entretenimiento y provecho con el propósito de ofrecérselos a ella. 
di amore con piacevolezza e molto riso di tutte [...] finché venne la sera che furon portati lor molti lumi e fu dato cena tanto sontuosa e di cibi sì delicati e deliziosi che tutti ne rimanevano stupiti. Dopo che ebbero cenato a molto agio e bevuto perfettissimi vini, furono anco un pezzo trattenuti tutti i congiugati finché fu l'ora di andare a dormire, nel qual tempo le dame deputate ai lor servigii con piacevol sorriso lor disse che tempo era venuto di dar refrigerio alle loro amorose fiamme e pigliar il premio delle tante fatiche, $[. .$.$] e quivi dando riposo agli infiammati cuori loro tutti questi novelli$ sposi e fedele amanti stettero pigliando il frutto desiderato de' loro amori consumando il matrimonio santo.

Por la noche, finalmente, los esposos consuman el matrimonio.

Después de un día pasado en el deleite del amor, al día siguiente el maravilloso palacio se desvanece en el aire (cap. 136) ${ }^{23}$. Reanudando el viaje, la compañía se detiene a almorzar en un fresco valle. Por la tarde, llega al lugar encantado, el Valle de Amor, «la valle la più amena e la meglio situata che si potesse vedere [...] piena di tanti frutti e fiori, di tante amene fontane, palagi ed edificii sì ricchi e sontuosì de los que salen dulces melodías.

$\mathrm{Al}$ día siguiente, los caballeros se arman y las princesas se visten ricamente. $\mathrm{La}$ maga Zirzea explica el secreto del desencantamiento: las princesas recién casadas tendrán un papel fundamental en la empresa, gracias a los arcos y flechas encantadas que la maga les proporciona:

Venuta la mattina, le belle principesse comparsero riccamente guarnite ei cavallieri si armarono [...] e alle graziose principesse ligarono i duo piccioli archi dorati alla centura con carcassi e frizze, che molto gli stavan bene $[\ldots]$.

Al final del valle, los recién casados llegan a un arroyo: para cruzarlo, los príncipes levantan a sus esposas en sus brazos:

[...] una riviera che pareva molto precipitosa e profonda, e non vi essendo ponte alcuno i duo principi vi entraron senza un timore al mondo, e viddero che l'acque gli arrivavano sino al ginocchio. Essi presero in braccio ciascuno la sua amata sposa e [...] si misero intrepidamente a passar la riviera, ma le due novelle spose non poteron far di non turbarsi [...] perciò che aveva la savia dato loro avviso che tenessero in modo le lor moglie alte in braccio ché non toccassero l'acqua [...]. Ma quando [...] vennero i duo principi [...] vicini alla riva, se gli opposero dieci selvaggi molto fieri in vista con bastoni forti e ferrati [...]. Fu lo spavento sì grande delle principesse, che tremavano tutte, [...] ma ricordatesi elle in tanto dello avviso che gli avea dato la savia Zirzea, presero i loro piccioli archi incantati [...] e postevi non senza difficultà le frizze, alzatesi nelle braccia dei loro mariti tiraron contra i selvaggi e avendone

23 «D’improviso sparse quello appartamento tutto, restando tutti i novelli sposi e spose tenendosi per mano nel cortile del gran palagio [...] e fu la maraviglia e il riso la mattina, che tutte le novelle spose si ritrovaron belle e vestite e acconcie e polite con tutti i muliebri loro ornamenti indosso, e [...] si ritrovarono a cavallo nei lor palafreni in atto di andar via e similmente $\mathrm{i}$ cavallieri si trovarono armati di tutte le loro arme e sopra i loro cavalli [...]. Quel bello e ricco palagio e quei vaghi e dilettosi giardini erano spariti tutti, né altro si vedeva nel sito di esso che erba verde di un spazioso prato». 
percosso un per una, cadero i selvaggi morti in terra, [...] ed elle ridendo si vantavano di aver potuto più di loro con quelli archi [...].

La iniciativa y la risa de las mujeres tienen un protagonismo especial en este episodio, como se ve también en las páginas que siguen, basadas en símbolos a la vez eróticos y paradisíacos: un peligroso árbol de manzanas, unas serpientes y un divertido desvestirse para proteger con sus faldas a los caballeros de la caída de los molestos frutos:

[...] si misero a caminare con i loro mariti così a piedi, e pervennero a uno stretto passo nel quale era un albero di maravigiosa grossezza e altezza pieno di grossissimi pomi [...]. I duo principi [...] si misero per passare oltre, ma fu la tempesta tanta che di quei spessi pomi gli cadevano addosso, che convenne che si ritirassero [...] che pareva che i pomi cadessero di cento miglia da alto palle di piombo. Molto ridevano le due principesse di questo caso [...].

Lo que la maga Zirzea había sugerido era «che voi alzate i lembi della prima vostra veste e con esso lembo coprendoci, ci riparate i colpi di questi pesanti pomi». Las princesas se ríen y dicen:

- Poiché gli è così, andiamo, e se così vi difendemo [...]. Ciascuna delle dame copriva con i lembi delle ricche vesti che portavano di sopra il suo amato marito, di che ne avvenne che cadendo i pomi a gran furia non toccavano le persone delle principesse, e con quelle falde delle lor vesti riparando i colpi dei pomi che sopra i cavallieri cadevano, e ricevevano quei pomi sì leggiermente, che parevan di penna e non di piombo.

En el capitulo siguiente, el 138, el manzano cae bajo los enérgicos golpes de los caballeros, que acometen a los monstruos que salen del tronco cortado. Sin embargo el «fierissimo serpente» y el «drago molto fiero» resultan encantados y facilmente derrotados por «le lor leggiadre spose» que con «i duo piccioli archi e postevi le frizze, percossero l'una il serpe e l'altra il drago, e incontanente caddero in terra morti, e in uno instante non si viddero più né essi drago e serpente né l'albero tagliato, né il tronco, anzi, apparve così aperto il passo» ${ }^{24}$.

En conclusión, en este recorrido se ha querido mostrar cómo la cultura de la corte, que se expresa en forma teatral delante de los mismos cortesanos, se fragua, en la literatura caballeresca, bajo el signo omnipresente de la gracia y de la belleza,

\footnotetext{
${ }^{24}$ Esto abre el acceso a los palacios del Valle, de donde comienzan a salir damas y caballeros liberados del encantamiento. La maga Zirzea acompaña a los recién casados al palacio de la encantadora enamorada, desconsolada ante la idea de perder a su amado. Finalmente, la Reina de Palomaro puede abrazar a su hijo liberado del Valle de Amor, y todos pueden regresar (caps. 137-138). Sobre los magos como principales tracistas de espectáculos cortesanos y autores de planes narrativos, cfr. Alberto del Río Nogueras, "Sobre magia y otros espectáculos cortesanos en los libros de caballerías", Medioevo y Literatura. Actas del V Congreso de la Asociación Hispánica de Literatura Medieval, 4 vols. (Granada: Universidad de Granada, 1995), IV, 137-149; y Bognolo, La finzione rinnovata, 183-211.
} 
manifestándose en acciones concretas, motivos narrativos recurrentes con variantes originales. A través de ejemplos tomados de dos textos del comienzo y del final del Renacimiento, entre España e Italia, se ha apreciado cómo en el cronotopo de la corte se suceden situaciones diferentes: conversación, fiesta, torneo, cacería, visita a palacios y jardines, arquitectura, pintura, música. Las historias fingidas son un espejo del mundo cortesano y de su práctica escénica en el que la realidad aristocrática coeva se refleja magníficamente amplificada. Además, la conversación y el humor vienen de voces femeninas que dominan el arte de la palabra, mostrando su agudeza de ingenio con motes, bromas y chistes. Hemos visto la corte retratada en momentos de ocio y pasatiempo: Amadís, tan competente manejando la lengua como la espada, nos ha proporcionado un ejemplo de conversación cortesana protagonizado por un personaje ejemplar. Unos capítulos del Esferamundi han manifestado un mundo festivo de hermosura y encanto. La sala mágica del Sol y de la Luna, en cuyas paredes están pintadas las aventuras de Amadís de Gaula, Amadís de Grecia, Florisel y todos los héroes del ciclo es un microcosmo cortesano sobre el que se proyecta entero su mundo novelesco. Los Seis libros de Esferamundi tejen un gran tapiz, análogo a las escenas pintadas en los frescos de los palacios, que ofrece una imagen dilatada de la corte desde el punto de vista de un escritor que vivió entre 1500 y 1580 y vio pasar mucha parte del siglo ${ }^{25}$. Mambrino Roseo da Fabriano pertenece a la generación siguiente a la de Castiglione: vio desaparecer la sociedad del primer Renacimiento italiano; su personal manera de reflejar novelísticamente la realidad de su época en una narración viva y alegre, eficaz en atraer al público y en «ricreare gli animi degli auditori e indurli a festa e riso», nos ofrece un extenso y detallado retrato desde una perspectiva digna de atención, una «messa in scena della forma propria della cultura della corte e delle sue pratiche quotidiane» ${ }^{26}$.

${ }^{25}$ En su juventud, Roseo sirvió como secretario al condotiero Malatesta Baglioni de Perugia y escribió un poema en octavas reales sobre la resistencia de la república de Florencia contra el asedio imperial de 1529. En los años treinta vivió en la Roma de los Farnese y de los Colonna, al servicio de la aristocracia, pero también de la industria del libro: sus editores, los hermanos Francesco y Michele Tramezzino, tenían la imprenta en Venecia y la librería en Roma, un animado centro humanístico del entorno papal. Fue un escritor profesional que vivió, pues, en el ambiente cosmopolita romano de la más elevada aristocracia europea. En el ámbito del PRIN 2017 Mapping Chivalry, el grupo de investigación Progetto Mambrino está realizando una edición digital interactiva del Esferamundi.

${ }^{26}$ Quondam, "Introduzione”, XXIX. Este artículo debe mucho a Alberto del Río Nogueras: ideas, sugerencias bibliográficas, pulimiento lingüístico y, sobre todo, amistad. 


\section{REFERENCIAS BIBLIOGRÁFICAS}

Aguilar Perdomo, M. a del Rosario, "La disposición escénica: algunas arquitecturas efímeras de los libros de caballerías españoles", en Destiempos.com. Caballerías (dossier), ed. Lillian von der Walde Moheno y Mariel Reinoso I., México: Grupo Destiempos, 23 (2009-2010): 69-103. Disponible en https://www.academia.edu/4807151/La disposici $\% \mathrm{C} 3 \% \mathrm{~B} 3 \mathrm{n}$ esc $\% \mathrm{C} 3 \% \mathrm{~A} 9$ nica algunas arquitecturas ef $\% \mathrm{C} 3 \%$ ADmeras de los libros de caballer $\%$ C3\%ADas espa \%C3\%B1oles [fecha de consulta: 4/5/2021].

Aguilar Perdomo, M. ${ }^{a}$ del Rosario, “"Espesuras y teximientos de jazmines': Los jardines en los libros de caballerías españoles, entre lo medieval y lo renacentista", eHumanista. Journal of Iberian Studies 16 (2010): 195-220, https://www.ehumanista.ucsb.edu/sites/secure.lsit.ucsb.edu.span.d7 eh/file s/sitefiles/ehumanista/volume16/11\%20ehumanista\%2016.aguilar perdono. pdf [fecha de consulta: 4/5/2021].

Aguilar Perdomo, M. ${ }^{a}$ del Rosario, "Jardín, fiesta y literatura caballeresca", en De cavaleiros e cavalarias. Por terras de Europa e Américas, ed. Lênia Márcia Mongelli (Sâo Paulo: Humanitas, 2012), 425-440.

Aguilar Perdomo, M. a del Rosario, "El palacio fuera de palacio: prácticas arquitectónicas y festivas en jardines históricos y literarios de la temprana Edad Moderna", Anales de Historia del Arte 23, 2 (2013): 415-429, https://doi.org/10.5209/rev ANHA.2013.v23.42844.

Aguilar Perdomo, M. ${ }^{a}$ del Rosario, "Plantamos jardines y edificamos la habitación del Monte': prácticas arquitectónicas y jardineras de la nobleza española en la Edad Moderna. Aproximación a los vínculos entre destinatarios, sus jardines y los libros de caballerías", Historias Fingidas 2 (2014): 49-86, https://doi.org/10.13136/2284-2667/17.

Antología de los libros de caballerías castellanos, ed. José Manuel Lucía Megías (Alcalá de Henares: Centro de Estudios Cervantinos, 2001).

Baldassarri, Guido, "Ut poesis pictura: cicli figurativi nei poemi epici e cavallereschi”, in La corte e lo spazio: Ferrara estense, ed. Giuseppe Papagno y Amedeo Quondam (Roma: Bulzoni, 1981).

Baldassarri, Guido, "Cavalerie della città di Ferrara”, Schifanoia 1 (1986): 100-125.

Biblioteca Digital Siglo de Oro (BIDISO) del Seminario Interdisciplinar para el Estudio de la Literatura Áurea Española (SIELAE) de la Universidade da Coruña, https://www.bidiso.es/Relaciones/ [fecha de consulta: 4/5/2021]. 
Bognolo, Anna, La finzione rinnovata. Meraviglioso, corte e avventura nel romanæo cavalleresco del primo Cinquecento spagnolo (Pisa: ETS, 1997).

Bognolo, Anna, "Il romanzo in una stanza. Le sale istoriate dello Sferamundi di Grecia", en Con gracia y agudeza. Studi offerti a Giuseppina Ledda, ed. Antonina Paba (Roma: Aracne, 2007), 85-104.

Bognolo, Anna, "Los salones pintados de la Historia di Sferamundi di Grecia de Mambrino Roseo da Fabriano", en Il mondo cavalleresco tra immagine e testo, ed. Claudia Demattè (Trento: Università di Trento, 2010), 85-113.

Bognolo, Anna, Giovanni Cara y Stefano Neri, Repertorio delle continuazioni italiane ai romanzi cavallereschi spagnoli. Ciclo di "Amadis di Gaula” (Roma: Bulzoni, 2013).

Calvete de Estrella, Juan Cristóbal, El felicíssimo viaje del muy alto y muy poderoso Príncipe don Phelippe, ed. Paloma Cuenca (Madrid: Sociedad Estatal para la Conmemoración de los Centenarios de Felipe II y Carlos V, 2001).

Cátedra, Pedro M., El sueño caballeresco. De la caballería de papel al sueño real de don Quijote (Madrid: Abada Editores, 2007).

Cuesta Torre, M. a Luzdivina, "Fiestas de boda en (algunos) libros de caballería", en Actas del VIII Congreso Internacional de la Asociación Hispánica de Literatura Medieval, ed. Margarita Freixas, Silvia Iriso y Laura Fernández (Santander: Consejería de Cultura del Gobierno de Cantabria-Asociación Hispánica de Literatura Medieval, 2000), 618-630.

Demattè, Claudia, y Alberto del Río Nogueras, "El escultor Leone Leoni diseña la Ínsula Firme según las reglas de Serlio en las bodas del marqués de Mantua (1561)", en La invención de las noticias. Las relaciones de sucesos entre la literatura y la información (siglos XVI-XVIII), ed. Giovanni Ciappelli y Valentina Nider (Trento: Università degli Studi di Trento, 2017), 829-842.

Devoto, Daniel, "Folklore y política en el Castillo Tenebroso", en Textos y contextos (Madrid: Gredos, 1974), 202-241.

Domenichelli, Mario, Cavaliere e gentiluomo. Saggio sulla cultura aristocratica in Europa (1513-1915) (Roma: Bulzoni, 2002).

Duce García, Jesús, Antología de autómatas en los libros de caballerías castellanos (Alcalá de Henares: Universidad de Alcalá, 2016). 
Early Modern Festival Books Database de la University of Oxford https:// festivals.mml. ox.ac.uk/index.php?page=home [fecha de consulta: 4/5/2021].

Eisenberg, Daniel, y M. ${ }^{a}$ Carmen Marín Pina, Bibliografía de los libros de caballerías castellanos (Zaragoza: Prensas Universitarias de Zaragoza, 2000).

Ferrario de Orduna, Lilia Elda, "Sobre El felicissimo viaje de Calvete de Estrella: una poética de las entradas reales. Ficción y realidad", Anuario de Letras 35 (1997): 461-487.

Ferrer Valls, Teresa, La práctica escénica cortesana: de la época del Emperador a la de Felipe III (Londres: Tamesis, 1991).

Ferrer Valls, Teresa, Nobleza y espectáculo teatral (1535-1622) (Valencia: UNED, 1993).

Frieder, Braden, Chivalry \& the Perfect Prince. Tournaments, Art, and Armor at the Spanish Habsburg Court (Kirksville: Truman State University Press, 2008).

Gamba Corradine, Jimena, Caballería, diplomacia y ficción entre España e Italia: "El Monte de Feronia” (1563) (Salamanca: Universidad de Salamanca, 2016).

Gamba Corradine, Jimena, Fiesta caballeresca en el Siglo de Oro. Estudio, edición, antología y catálogo (Zaragoza: Institución Fernando el Católico, 2017).

Köhler, Erich, La aventura caballeresca. Ideal y realidad en la narrativa cortés (Barcelona: Sirmio, 1990).

La terza parte dell'bistoria dello inuitissimo principe Sferamundi di Grecia nuouamente ritrouata, e ridotta nella lingua italiana, per M. Mambrino Roseo da Fabriano (Venecia: Michele Tramezzino, 1563).

López Estrada, Francisco, "Fiestas y literatura en los Siglos de Oro: la Edad Media como asunto 'festivo' (el caso del Quijote)", Bulletin Hispanique 84 (1982): 291 327, https://doi.org/10.3406/hispa.1982.4475.

Lucía Megías, José Manuel, "Libros de caballerías castellanos: textos y contextos", Edad de Oro 21 (2002): 9-60, https://doi.org/10.15366/edadoro2002.21.

Marín Pina, M. ${ }^{a}$ Carmen, "Las cartas de amor caballerescas como modelos epistolares", en La recepción del texto literario (Coloquio. Abril de 1986), ed. JeanPierre Étienvre y Leonardo Romero (Zaragoza: Casa de VelázquezUniversidad de Zaragoza, 1988), 11-24. 
Martín Romero, José Julio, "El Ornamento de princesas: un diálogo sobre la educación femenina de Feliciano de Silva", Tirant. Butlletí informatiu $i$ bibliográfic de la literatura de cavalleries 10 (2007): s. p., http://parnaseo.uv.es/tirant/butlleti.10/ art.romero feliciano.htm [fecha de consulta: 4/5/2021].

Mottola, Anthony C., The "Amadís de Gaula" in Spain and in France, tesis doctoral (Fordham University, 1962).

Neri, Stefano, "Conversazioni, giochi, feste e commedie", en Anna Bognolo, Giovanni Cara y Stefano Neri, Repertorio delle continuazioni italiane ai romanæi cavallereschi spagnoli. Ciclo di "Amadis di Gaula" (Roma: Bulzoni, 2013), 128-139.

O’Connor, John J., "Amadís de Gaule” and Its Influence on Elizabethan Literature (New Brunswick: Rutgers University Press, 1970).

Pena Sueiro, Nieves, "Los casamientos del príncipe Felipe de Austria y María Manuela de Portugal en las relaciones de sucesos", en Festina Lente. Augusta empresa correr a espacio. Studia in honorem Sagrario López. Poza, ed. Nieves Pena Sueiro y Carlota Cristina Fernández Travieso (La Coruña: Universidade da Coruña-BIDISO, 2019), 247-262.

Place, Edwin B., "El Amadís de Montalvo como manual de cortesanía en Francia", Revista de Filología Española 38 (1954): 151-169.

Quondam, Amedeo, "Introduzione" a Baldassarre Castiglione, Il libro del Cortegiano (Milán: Garzanti, 1981), VII-LI.

Quondam, Amedeo, La conversaz̧ione. Un modello italiano (Roma: Donzelli, 2007).

Río Nogueras, Alberto del, "Sobre magia y otros espectáculos cortesanos en los libros de caballerías", Medioevo y Literatura. Actas del V Congreso de la Asociación Hispánica de Literatura Medieval, 4 vols. (Granada: Universidad de Granada, 1995), IV, 137-149.

Río Nogueras, Alberto del, "Libros de caballerías y burlas cortesanas. Sobre algunos episodios del Cirongilio de Traciay del Clarián de Landanis", en Literatura caballeresca entre España e Italia (del "Orlando" al "Quijote"), ed. Folke Gernert (Salamanca-Kiel: Seminario de Estudios Medievales y Renacentistas-Sociedad de Estudios Medievales y Renacentistas-CERES de la Universidad de Kiel, 2004), 53-65.

Río Nogueras, Alberto del, "Motivos folclóricos y espectáculo caballeresco: el príncipe Felipe en las fiestas de Binche en 1549", Revista de Poética Medieval 26 (2012): 285-302, https://doi.org/10.37536/RPM.2012.26.0.30676. 
Río Nogueras, Alberto del, "En el principio fue el desfile. Entretenimiento cortesano y fastos ciudadanos en los libros de caballerías del primer tercio del siglo XVI", en El teatro en tiempos de Isabel y Juana (1474-1517), ed. Felipe B. Pedraza Jiménez (Cuenca: Universidad de Castilla-La Mancha, 2017), 73-93.

Rodríguez de Montalvo, Garci, Amadís de Gaula, ed. Juan Manuel Cacho Blecua (Madrid: Cátedra, 2008, 5. ${ }^{\mathrm{a}}$ ed.).

Roubaud, Sylvia, "Les fêtes dans les romans de chevalerie hispanique", en Les fêtes de la Renaissance. III, ed. Jean Jacquot (París: CNRS, 1975), 313-340.

Roubaud, Sylvia, "Libros de caballerías en Francia", en Amadís de Gaula, 1508. Quinientos años de libros de caballerías, ed. José Manuel Lucía Megías (Madrid: Biblioteca Nacional de España, 2008), 319-331.

Serrano, Florence, "The Trésor des livres d'Amadis as an Anthology of Speeches", en Anthologies of Historiographical Speeches from Antiquity to Early Modern Times. Rearranging the Tesserae, dir. Juan Carlos Iglesias-Zoido y Victoria Pineda (Leiden-Boston: Brill, 2017), 357-378.

Visiones de un imperio en fiesta, ed. Inmaculada Rodríguez Moya y Víctor Mínguez Cornelles (Madrid: Fundación Carlos Amberes, 2016).

Watanabe-O'Kelly, Helen, and Anne Simon, Festivals and Ceremonies. A Bibliography of Works Relating to Court, Civic and Religious Festivals in Europe, 1500-1800 (Londres-Nueva York: Mansell, 2000).

Watanabe-O'Kelly, Helen, Margaret Shewring, James Ronald Mulryne, Sarah Knight y Elizabeth Goldring, Europa Triumphans. Court and Civic Festivals in Early Modern Europe (Londres: MHRA, 2004).

Zoppi, Federica, "Risa y mujer: motivos de humorismo femenino en el ciclo de los Palmerines", Historias Fingidas 8 (2020): 223-255, https://doi.org/10.13136/22 $\underline{84-2667 / 156 .}$.

Recibido: 23 de febrero de 2021

Aprobado:25 de marzo de 2021 